\title{
Determination of Carboxylesters by Indirect Photometric Ion Chromatography with an On-Line Enzyme Immobilized Column
}

\author{
Kazuichi Hayakawa, Seiji Nakamura, Kotoe Inaki and Motoichi Miyazaki \\ Faculty of Pharmaceutical Sciences, Kanazawa University, Takara-machi, Kanazawa 920, Japan
}

\begin{abstract}
Carboxylesters, carboxylic and inorganic anions were determined separately by photometric ion chromatography with an enzyme immobilized column. In the system, a carboxylesterase immobilized column $(4.6 \mathrm{~mm}$ i.d. $\times 10 \mathrm{~mm})$, which converted carboxylesters to carboxylic anions completely, was set between a sample injector and an analytical column. The other chromatographic conditions were as follows: an anion exchanger-type separation column $\left(4.6 \mathrm{~mm}\right.$ i.d. $\times 250 \mathrm{~mm}$ ); phthalate- $N$-2-hydroxyethylpiperazine- $N^{\prime}$-2-ethanesulfonic acid elvent $(\mathrm{pH} 6.5)$; an oven of temperature $40^{\circ} \mathrm{C}$; a flow rate of $1.0 \mathrm{ml} / \mathrm{min}$; $280-\mathrm{nm}$ UV detection; and an injection volume of $20 \mu \mathrm{l}$. Calibration curves for ethyl esters of acetate, propionate, butyrate and isovalerate were linear with the range $5 \times 10^{-10} \mathrm{~mol}$ to $1 \times 10^{-7} \mathrm{~mol}$ according to the peak-height method; their detection limits were $10^{-10} \mathrm{~mol}$ levels. The present method was applied for the determination of carboxylesters in practical samples.
\end{abstract}

Keywords Indirect photometric ion chromatography, enzyme immobilized column, carboxylester, carboxylesterase, carboxylic acid

Ion chromatography (IC) ${ }^{1}$ has been widely used in the determination of ionic compounds. However neither non-ionic compounds, such as carboxylester do not give any signal, and large molecular ionic compounds, such as hyaluronic acid, have strong retentions of the column in IC. These two facts represent limitations on the application of IC. However, if such compounds are automatically converted to ionic compounds of small molecular size before being passed through a separation column, they can be determined sensitively by IC. In this respect, an enzyme immobilized column is a useful converter owing to its high, selective activity. Both conductivity detection (CD) and photometric detection (PD) ${ }^{2}$ are popular methods in non-suppressed (single-column) IC. The authors have used PD-IC for the determination of organic as well as inorganic ions ${ }^{3-7}$, since it can be performed on a conventional high performance liquid chromatography (HPLC) apparatus equipped with an ultraviolet (UV) absorbance detector. For the use of an enzyme whose optimum $\mathrm{pH}$ is neutral or alkaline PD-IC is more suitable than CD-IC, since its sensitivity for such weak acids as carboxylates and bicarbonate is low within the same pH region. ${ }^{8}$ Accordingly, the authors constructed an on-line system with an enzyme immobilized column and conventional PD-IC. By using the enzyme immobilized column between a sample injector and a separation column, both non-ionic and large molecular ionic compounds could be converted to ionic compounds of small molecules which are separately deter- mined by the following separation column and UV absorbance detector.

Although there have been reports concerning CD-IC using enzyme immobilized columns ${ }^{9-11}$, they were offline systems, enzyme immobilized columns were used under different conditions from those of eluents for CD-IC. The present on-line system is superior to the off-line system described above with regard to the following advantages: only one pumping system, common eluent conditions for both enzyme immobilized and separation columns, a small sample volume, and easy operation.

The purpose of this report is to describe the effectiveness of the proposed system regarding the determination of low molecular carboxylesters as sample analytes. Additionally, the influence of the enzyme immobilized column on chromatographic parameters is discussed, since this method is a new approach for using an enzyme immobilized column just before the separation column.

\section{Experimental}

\section{Reagents}

Phthalic acid and sodium salts of phthalate, benzoate, benzenesulfonate and 1,5-naphthalenedisulfonate were purchased from Wako Pure Chemicals (Osaka, Japan) and of reagent grade. Eluents were prepared by dissolving them in distilled deionized water. The pH 
was adjusted with $N$-2-hydroxyethylpiperazine- $N^{\prime}-2$ ethanesulfonic acid (HEPES)-sodium hydroxide buffer. The eluent was treated with a Fuji FM-45 membrane filter (pore size of $0.45 \mu \mathrm{m}$ ) before use. Ethyl esters of acetate, propionate, butyrate and isovalerate of reagent grade were purchased from Wako Pure Chemicals. Their standard solutions were prepared by dissolving them supersonically into distilled-deionized water. Carboxylesterase (EC 3.1.1.1) solution (11 mg protein $/ \mathrm{ml}$ ) was purchased from Sigma Chemical Co. (St. Louis, MO, U.S.A.). All othter chemicals used wcre of reagent grade.

\section{Apparatus and chromatographic conditions}

The system consisted of a Shimadzu LC-6A pump (Kyoto, Japan); a Rheodyne 7125 injector (Cotati, CA, U.S.A.) with a loop of $20 \mu \mathrm{l}$; an enzyme immobilized column (4.6 mm i.d. $\times 10 \mathrm{~mm}$, stainless steel); a separation column $(4.6 \mathrm{~mm}$ i.d. $\times 250 \mathrm{~mm}$, stainless steel) packed with MCI GEL SCA-03 (Mitsubishi Chemical, Tokyo, Japan) anion exchanger (styrene-divinylbenzene copolymer, anion exchange capacity of $0.03 \mathrm{meq} . / \mathrm{g}$ ) or MCI GEL SCA-02 anion exchanger (styrene-divinylbenzene copolymer, anion exchange capacity of 0.01 meg./g); a Shimadzu CTO-6AS column oven; a Shimadzu SPD-6AV spectrophotometric detector; and a Shimadzu C-R3A integrator. A schematic diagram of the system is shown in Fig. 1.

The typical eluents were $1.0 \times 10^{-3} \mathrm{M}$ phthalate$1.5 \times 10^{-4} \mathrm{M}$ HEPES (pH 6.5) for the MCI GEL SCA-03

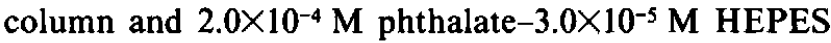
(pH 6.5) for the MCI GEL SCA-02 column. Other conditions of the system were as follows: a flow rate of $1.0 \mathrm{ml} / \mathrm{min}$; a $280-\mathrm{nm}$ UV detection; and an oven temperature of $40^{\circ} \mathrm{C}$. Nitrogen gas (purity over $99.99 \%$ ) was purged into the eluent in order to remove any atmospheric carbon dioxide. ${ }^{12}$ Upside-down chromatograms were recorded by changing the polarity.

\section{Preparation of carboxylesterase (CE) immobilized column}

$N$-Hydroxysuccinimide (NHS) method:13 a CE solution (7.1 $\mathrm{mg}$ in $4 \mathrm{ml}$ of $3.2 \mathrm{M}$ ammonium sulfate) was dialyzed against $1000 \mathrm{ml}$ of a $0.1 \mathrm{M} 3-(N$-morpholino)propanesulfonic acid (MOPS) buffer $(\mathrm{pH} 7.5)$ at $4^{\circ} \mathrm{C}$ overnight so as to prevent ammonium ions from interfering with the immobilization. One gram of Affiprep 10 ( $N$-hydroxysuccinimide ester-form resin of $40-$ $60 \mu \mathrm{m}$ diameter, Bio-Rad, Tokyo, Japan) was added to

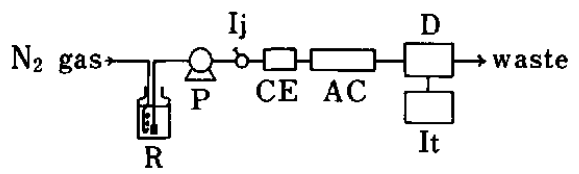

Fig. 1 Schematic diagram of the system. R, eluent reservoir; $P$, pump; Ij, injector; CE, carboxyl esterase immobilized column; AC, analytical column; D, UV absorbance detector; It, integrator. the dialyzed $\mathrm{CE}$ solution and the mixture was slowly stirred for $2 \mathrm{~h}$ at $4^{\circ} \mathrm{C}$. After the supernatant was decanted, $7 \mathrm{ml}$ of the MOPS buffer and $0.1 \mathrm{ml}$ of $1 \mathrm{M}$ ethanolamine were added successively to the resin and the mixture was slowly stirred for $1 \mathrm{~h}$ at $4^{\circ} \mathrm{C}$. The resin was then filtered and washed with the MOPS buffer.

Glutaraldehyde (GA) method: ${ }^{14}$ The same CE solution as described above was dialyzed against $1000 \mathrm{ml}$ of $0.1 \mathrm{M}$ phosphate buffer ( $\mathrm{pH} 8.0$ ) at $4^{\circ} \mathrm{C}$ overnight. On the other hand, one gram of CPG-10 (controlled porosity glass beads of $125-177 \mu \mathrm{m}$ diameter with a pore size of $120 \AA$, Electro-Nucleonics, NJ, U.S.A.) alkylated with 3-aminopropyltriethoxysilane was added to $5 \mathrm{ml}$ of a $2.5 \%$ glutaraldehyde solution and the mixture was slowly stirred for $1 \mathrm{~h}$ at room temperature. After being filtered and washed with water, the beads were added to the dialyzed CE solution and the mixture was slowly stirred for $2.5 \mathrm{~h}$ at $4^{\circ} \mathrm{C}$. These two steps were performed in a glove box filled with a nitrogen gas flow of $50 \mathrm{ml} / \mathrm{min}$. The beads were filtered and washed with the phosphate buffer.

With CE immobilized supports made by the two methods, stainless-steel columns (4.6 mm i.d.) or Teflon tubings $(2.0 \mathrm{~mm}$ i.d.) were packed using a slurry technique.

\section{Assay of enzyme activity}

The activity (unit) of the CE immobilized support (or intact CE) was determined as follows. ${ }^{15}$ Fifty milliliters of the substrate solution $\left(5.0 \times 10^{-4} \mathrm{M}\right.$ 4-nitrophenyl acetate in $1.0 \times 10^{-2} \mathrm{M}$ phosphate buffer $(\mathrm{pH} \mathrm{8.0)})$ in a flask was slowly stirred at $25^{\circ} \mathrm{C}$. The solution was circulated through a Shimadzu SPD-6AV spectrophotometer at a flow rate of $1.0 \mathrm{ml} / \mathrm{min}$. After the addition of CE immobilized supports (or intact CE) into the flask, the concentration of 4-nitrophenol was determined by monitoring the absorbance at $430 \mathrm{~nm}$. On the other hand, $50 \mathrm{ml}$ of ethyl butyrate $\left(0-1.0 \times 10^{-4} \mathrm{M}\right)-1 \times$ $10^{-2} \mathrm{M}$ HEPES buffer ( $\mathrm{pH}$ 6.5) was slowly stirred at $25^{\circ} \mathrm{C}$. After the addition of CE immobilized supports (or intact $\mathrm{CE}$ ), the concentration of butyrate was determined to be a hydrolyzed product by conventional PD-IC. ${ }^{5}$ The Michaelis constant was calculated from the initial hydrolysis rate.

The relative activities (relative hydrolysis rate) of the CE immobilized column were measured as follows. Ethyl butyrate $\left(1.0 \times 10^{-3} \mathrm{M}\right)$ dissolved in carrier solutions was pumped through the $\mathrm{CE}$ column at a flow rate of $1.0 \mathrm{ml} / \mathrm{min}$. The concentration of butyrate in the eluate was determined by conventional PD-IC. ${ }^{5}$

\section{Extraction of carboxylesters}

Carboxylesters in strawberry essence, toothpaste and pineapple juice were extracted into water by nitrogen gas purging. ${ }^{16}$ The extraction system consisted of a nitrogen gas bomb, a sample flask (pear-shaped glass, inner volume of $1000 \mathrm{ml}$ ) and a trapping bottle (gaswashing glass bottle) containing $100 \mathrm{ml}$ of $2.0 \times 10^{-4} \mathrm{M}$ disodium phthalate as a trapping solution. The 
trapping bottle was kept in an ice-water bath. Pineapple juice $(100 \mathrm{ml})$, toothpaste $(30 \mathrm{~g}$ dissolved in $100 \mathrm{ml}$ of water) or strawberry essence $(4 \mathrm{ml}$ dissolved in $100 \mathrm{ml}$ of water) was poured into a sample flask. After setting the sample flask in a water bath kept at $60^{\circ} \mathrm{C}$, nitrogen was purged into the sample solution at a flow rate of $100 \mathrm{ml} / \mathrm{min}$ for $1 \mathrm{~h}$. An aliquot $(20 \mu \mathrm{l})$ of the trapping solution containing carboxylesters was injected into the present system.

\section{Results and Discussion}

In the beginning the characteristics of CE immobilized by the two methods were compared. The amounts of immobilized CE were $1.90 \mathrm{mg}$ of protein $/ \mathrm{g}$ of support by the NHS method and $1.62 \mathrm{mg}$ of protein $/ \mathrm{g}$ of support by the GA method, respectively. The activity of the former ( 21 units/mg of protein) was higher han that of the latter (15 units/ $\mathrm{mg}$ of protein) although intact CE had a higher activity (45 units/mg of protein), as shown in Table 1. Moreover, the enzyme activity of the former remained longer than that of the latter. Therefore, the NHS method was used for $\mathrm{CE}$ immobilization in the following experiments. Both the decrease in the activity and the increase in the Michaelis constant by immobilization might be ascribed to a conformational change in $\mathrm{CE}$.

In the present on-line system, it is necessary to use an eluent which does not interfere with the enzyme reaction. The relative activities of the $\mathrm{CE}$ immobilized column were compared with such popular UV-absorbing eluents as benzoate, phthalate, benzenesulfonate and 1,5-naphthalenedisulfonate (Table 2). ${ }^{1,17-20}$ The activities with these eluents were still more than $63 \%$ at $1 \times 10^{-2} \mathrm{M}$, which was much higher than that usually used, although the activities slightly decreased upon increasing their concentrations. This result suggested

Table 1 Characteristics of immobilized carboxyl esterase

\begin{tabular}{|c|c|c|}
\hline \multicolumn{2}{|c|}{ Immobilized } & \multirow{2}{*}{ Intact } \\
\hline by NHS method & by GA method & \\
\hline $\begin{array}{l}\text { Immobilized amount } \\
1.90 \mathrm{mg} \text { protein } / \\
\text { g support }\end{array}$ & $\begin{array}{l}1.62 \mathrm{mg} \text { protein/ } \\
\mathrm{g} \text { support }\end{array}$ & \\
\hline $\begin{array}{l}\text { Enzyme activity } \\
21 \text { unit } / \mathrm{mg} \\
\text { protein }\end{array}$ & $\begin{array}{l}15 \text { unit } / \mathrm{mg} \\
\text { protein }\end{array}$ & $\begin{array}{l}45 \text { unit } / \mathrm{mg} \\
\text { protein }\end{array}$ \\
\hline $\begin{array}{l}\text { Michaelis constant } \\
5.6 \mathrm{mM}\end{array}$ & $1.0 \mathrm{mM}$ & $0.2 \mathrm{mM}$ \\
\hline $\begin{array}{l}\text { Repeatability } \\
\text { Yes }\end{array}$ & Yes & No \\
\hline $\begin{array}{l}\text { (Life time) } \\
\quad \text { (months) }\end{array}$ & $(\text { days })^{a}$ & \\
\hline
\end{tabular}

a. CE immobilized supports were packed in the stainless steel column of $4.6 \mathrm{~mm}$ i.d. $\times 10 \mathrm{~mm}$. that all of the eluents tested might be available for the present purpose. Phthalate was used as an eluent in the present system, since it has been shown to be the most effective eluent in the determination of low molecularweight carboxylate anions which were hydrolyzed products with carboxylesterase. ${ }^{5}$

The $\mathrm{pH}$ is another important factor which affects enzyme activity. The activities of a $\mathrm{CE}$ immobilized column were compared with a $1.0 \times 10^{-2} \mathrm{M}$ phthalate eluent. The $\mathrm{pH}$ was adjusted to between 4.0 and 9.0 by the addition of a $1.0 \times 10^{-2} \mathrm{M}$ HEPES buffer. The activity increased with an increase of $\mathrm{pH}$ in the acidic region and reached a maximum at $\mathrm{pH} 7$. The activity was maintained in a weak basic $\mathrm{pH}$ region (Table 3 ). An eluent of pH around 7 was also suitable for a sensitive determination owing to the following reason. The peak area of carboxylic acid increases as the result of an increase in the eluent $\mathrm{pH}$ in PD-IC since the ionic fraction of weak acid increases with an increase in the eluent $\mathrm{pH}^{8}$ Therefore, the eluent $\mathrm{pH}$ was adjusted to be 6.5 in the following experiments.

Table 2 Effect of eluent species on the activity of the CEcolumn $^{\mathrm{a}}$

\begin{tabular}{lcc}
\hline \multicolumn{1}{c}{ Carrier solution } & $\begin{array}{c}\text { Concentration/ } \\
\mathrm{M}\end{array}$ & $\begin{array}{c}\text { Relative } \\
\text { activity }^{\mathrm{b}}\end{array}$ \\
\hline Distilled-deionized water & & 1 \\
Benzoate & $10^{-4}$ & 0.97 \\
& $10^{-3}$ & 0.88 \\
Phthalate & $10^{-2}$ & 0.76 \\
& $10^{-4}$ & 0.95 \\
& $10^{-3}$ & 0.90 \\
Benzenesulfonate & $10^{-2}$ & 0.70 \\
1,5-Naphthalenedisulfonate & $10^{-2}$ & 0.93 \\
\hline
\end{tabular}

a. One $\mathrm{ml}$ of $1.0 \times 10^{-3} \mathrm{M}$ ethyl butyrate in each eluent was pumped into the CE-column $(4.6 \mathrm{~mm}$ i.d. $\times 10 \mathrm{~mm})$ at a flow rate of $1.0 \mathrm{ml} / \mathrm{min}$. An aliquot $(20 \mu \mathrm{l})$ of the effluent was injected into the conventional PD-IC. ${ }^{5}$

b. Relative peak area of butyrate to that with distilled-deionized water as a carrier solution.

Table 3 Effect of $\mathrm{pH}$ of the phthalate eluent ${ }^{\mathrm{a}}$ on the activity of the CE-column

\begin{tabular}{cc}
\hline $\mathrm{pH}$ & Relative activity $^{\mathrm{b}}$ \\
\hline 4 & 0 \\
5 & 0.37 \\
6 & 0.83 \\
7 & 1 \\
8 & 0.96 \\
9 & 0.95 \\
\hline
\end{tabular}

a. The concentrations of phthalate and HEPES were $1.0 \times 10^{-2}$ $\mathrm{M}$ and $1.0 \times 10^{-2} \mathrm{M}$, respectively.

b. Relative peak area of butyrate to that at $\mathrm{pH} 7$. Other conditions were the same as in Table 2. 
It is assumed that the activity of an enzyme immobilized column becomes higher and its lifetime becomes longer with an increase in the column volume. On the contrary, the number of theoretical plates decreases with an increase in the enzyme column volume. When $20 \mu \mathrm{l}$ of ethyl butyrate of $10 \times 10^{-3} \mathrm{M}$ was injected into the $\mathrm{CE}$ immobilized column with the phthalate eluent at a flow rate of $1.0 \mathrm{ml} / \mathrm{min}$, the column size of $2 \mathrm{~mm}$ i.d. $\times 10 \mathrm{~mm}$ was quite sufficient to completely hydrolyze ethyl butyrate. A $4.6 \mathrm{~mm}$ i.d. $\times 10$ $\mathrm{mm}$ column was mainly used in the present system and its activity was still high enough to completely hydrolyze carboxylesters after successive use for 8 months.

From the results described above, the conditions of the present on-line system of PD-IC with the CE immobilized column were determined as shown in Fig. 1. The system has the following systematic advantages. First of all, it comprises a conventional one-pumping HPLC apparatus equipped with a UV detector. The present system requires a sample volume of less than $100 \mu$ l (the volume of the sample loop is $20 \mu \mathrm{l})$. This volume is much smaller than that of the off-line system, which required more than $1 \mathrm{ml} .^{9-11}$ The operation of the present system is easier than that of the off-line system, since the enzyme immobilized column of the latter system must be washed after every injection.

The present system was able to determine not only carboxylesters but also organic and inorganic anions simultaneously. Typical chromatograms were shown in Fig. 2 as the comparison of the system with and without CE-column. Both ethyl acetate and ethyl isovalerate were not detected without a $\mathrm{CE}$ immobilized column (Fig. 2A). While two ethyl carboxylates were observed respectively as peaks of acetate and isovalerate by the $\mathrm{CE}$ column (Fig. 2B). Carboxylate and inorganic anions were detected at their own reten-
A

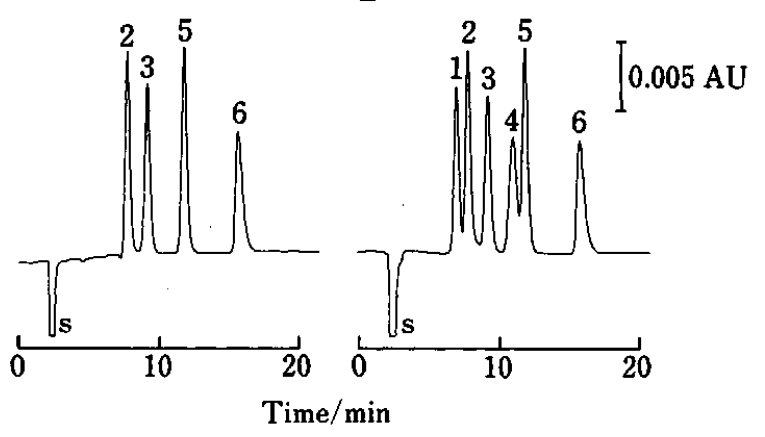

Fig. 2 Chromatograms of ethyl carboxylates, carboxylate anions and inorganic anions with and without the CEcolumn. A, without the CE-column; B, with the CE-column. Peaks: s, system peak; 1, ethyl acetate; 2 , propionate; 3 , butyrate; 4 , ethyl isovalerate; 5 , chloride; 6 , nitrite. Sample amount, $1.0 \times 10^{-8} \mathrm{~mol}$ each. Other conditions were described in the text. tion times in both systems with the peak of water dip at the void volume.

Next, chromatographic parameters of the system with and without a CE immobilized column were compared in order to estimate the influence of an enzyme immobilized column positioned just before a separation column. Four ethyl carboxylates used as standards were detected separately, as shown in Fig. 3. Their apparent theoretical plate numbers were all within the range 2200 to 2600 with the CE immobilized column, as listed in Table 4 . These numbers might be quite sufficient in practical analyses, though the CE immobilized column decreased the column efficiency by $7-25 \%$. These percentages of the decrease ascribed to the dead volume might be made smaller by reducing the volume of the enzyme immobilized column.

It was interesting that the retention times of ethyl carboxylates were the same as those of the corresponding carboxylic acids (Table 5). This result suggested that the reaction time of $\mathrm{CE}$ and ethyl carboxylates was sufficiently short to be negligible and that the adsorp-

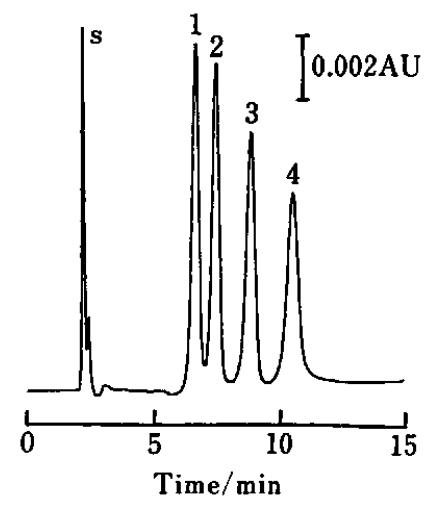

Fig. 3 Typical chromatogram of four ethyl carboxylates. Peaks: s, system peak; 1 , ethyl acetate; 2 , ethyl propionate; 3 , ethyl butyrate; 4 , ethyl isovalerate. Other conditions were the same as in Fig. 2.

Table 4 Apparent theoretical plate numbers for ethyl carboxylates and carboxylic acids with and without the CE-column

\begin{tabular}{lll}
\hline \multirow{2}{*}{ Injected compound } & \multicolumn{2}{c}{ CE-column } \\
\cline { 2 - 3 } & with & without \\
\hline Ethyl acetate & 2400 & N.D. ${ }^{\mathrm{a}}$ \\
Acetic acid & 2100 & 2900 \\
Ethyl propionate & 2600 & N.D. \\
Propionic acid & 2400 & 3000 \\
Ethyl butyrate & 2400 & N.D. \\
Butyric acid & 2600 & 2800 \\
Ethyl isovalerate & 2200 & N.D. \\
Isovaleric acid & 2500 & 2700 \\
\hline
\end{tabular}

a. Not detected.

See text for the chromatographic conditions. 
Table 5 Retention times of ethyl carboxylates and carboxylic acids obtained with the CE-column plus separation column

\begin{tabular}{lc}
\hline Injected compound & Retention time $/ \mathrm{min}$ \\
\hline Ethyl acetate & 6.8 \\
Acetic acid & 6.8 \\
Ethyl propionate & 7.6 \\
Propionic acid & 7.6 \\
Ethyl butyrate & 8.9 \\
Butyric acid & 8.9 \\
Ethyl isovalerate & 10.6 \\
Isovaleric acid & 10.6 \\
\hline
\end{tabular}

See text for the chromatographic conditions.

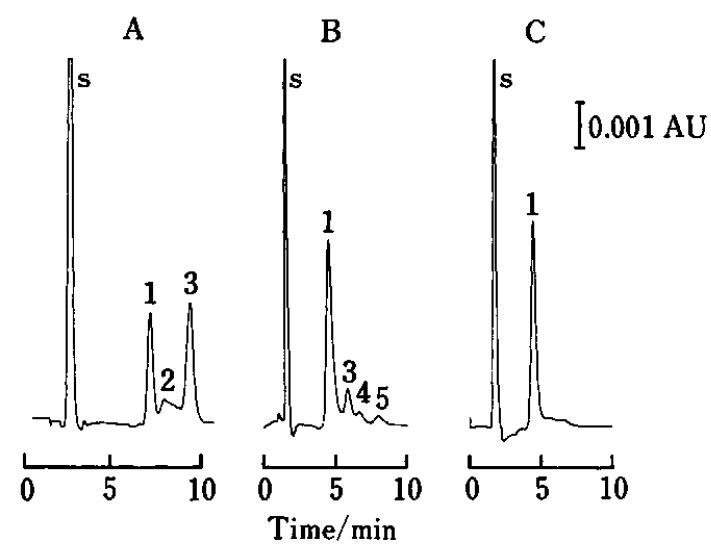

Fig. 4 Chromatograms of strawberry essence, toothpaste and pineapple juice. A, strawberry essence; B, toothpaste; C, pineapple juice. Separation column and eluent: A, MCI GEL SCA-03 (4.6 mm i.d. $\times 250 \mathrm{~mm}), \quad 1.0 \times 10^{-3} \mathrm{M}$ phthalate$1.5 \times 10^{-4} \mathrm{M}$ HEPES (pH 6.5); B, MCI GEL SCA- $02(4.6 \mathrm{~mm}$ i.d. $\times 250 \mathrm{~mm}), \quad 2.0 \times 10^{-4} \mathrm{M}$ phthalate- $3.0 \times 10^{-5} \mathrm{M}$ HEPES (pH 6.5); $\mathrm{C}$, the same as in B. Peaks: s, system peak; 1 , acetate ester; 2 , bicarbonate; 3 , propionate ester; 4 , butyrate ester; 5 , isovalerate ester.

tion of esters to the resin was sufficiently small. The retentions of carboxylesters may be stronger than those of carboxylate anions by the use of hydrophobic resins.

The detection limits of the four ethyl carboxylates were in the range $3 \times 10^{-10} \mathrm{~mol}$ (ethyl acetate) to $5 \times 10^{-10}$ mol (ethyl isovalerate), since the signal-to-noise ratio was 3. The calibration curves were linear from $1 \times 10^{-9}$ mol to $1 \times 10^{-7} \mathrm{~mol}$ according to the peak-height method. The linearity was not restricted by the activity of the CE immobilized column but, rather, by the capacity of the separation column over $1 \times 10^{-7} \mathrm{~mol}$.

Carboxylesters in strawberry essence, toothpaste and pineapple juice were analyzed as applications of the present method after the extraction of esters into water. The extraction method with nitrogen gas purging has been used for the isolation of volatile compounds from several foods. ${ }^{5}$ The recoveries of ethyl esters of acetate, propionate, butyrate and isovalerate by the method were all over $70 \%$. Esters of acetate and propionate were detected in strawberry essence (Fig. 4A). Esters of acetate, butyrate and isovalerate were detected in toothpaste (Fig. 4B). Acetate ester was detected in pineapple juice (Fig. 4C). It should be emphasized that the technique of an enzyme immobilized column with PD-IC is applicable to other compounds. Such studies using other enzymes have been carried out; further details regarding these studies will be presented elsewhere.

\section{References}

1. H. Small, T. S. Stevens and W. C. Bauman, Anal. Chem., 47, 1801 (1975)

2. H. Small and T. E. Miller, Jr., Anal. Chem., 54, 462 (1982).

3. M. Miyazaki, K. Hayakawa and S. Choi, J. Chromatogr., 323, 443 (1985).

4. K. Hayakawa, H. Hiraki and M. Miyazaki, Bunseki Kagaku, 34, T71 (1985).

5. I. Yoshida, K. Hayakawa and M. Miyazaki, Eisei Kagaku, 31, 317 (1985).

6. K. Hayakawa, T. Sawada, K. Shimbo and M. Miyazaki, Anal. Chem., 59, 2241 (1987).

7. K. Hayakawa and M. Miyazaki, LC-GC 6, 508 (1988).

8. S. Nakamura, N. Imaizumi, K. Hayakawa and $\mathbf{M}$. Miyazaki, Bunseki Kagaku, 38, 573 (1989).

9. S. Uchiyama, Y. Tohfuku, S. Suzuki and G. Muto, Anal. Chim. Acta, 174, 313 (1985).

10. S. Uchiyama, Y. Tohfuku, S. Suzuki and G. Muto, Bunseki Kagaku, 37, 109 (1988).

11. S. Uchiyama, Y. Tohfuku, S. Suzuki and G. Muto, Anal. Sci., 4, 423 (1988).

12. K. Hayakawa, S. Kitamoto, S. Nakamura, N. Okobo and M. Miyazaki, J. Chromatogr., 481, 323 (1989).

13. Manual book for Affi-prep 10, Bio-Rad.

14. M. Masoom and A. Townshend, Anal. Chim. Acta, 166, 111 (1984).

15. Y. Kobayashi, Seikagaku, 36, 335 (1964).

16. R. Saijo and Y. Kuwabara, Nogei Kagaku, 38, 595 (1964).

17. K. Hayakawa, H. Hiraki and M. Miyazaki, Bunseki Kagaku, 32, 504 (1983).

18. S. Motomizu, I. Sawatani, T. Hironaka, M. Oshima and K. Tohei, Bunseki Kagaku, 36, 77 (1987).

19. Y. Yokoyama and H. Sato, J. Chromatogr. Sci., 26, 561 (1988).

20. A. Jardy, M. Caude, A. Diop, C. Curvale and R. Rosset, J. Chromatogr., 439, 137 (1988).

(Received July 22, 1989) (Accepted August 11, 1989) 